\title{
Natural Fibre Sandwich Composite Panels-Analysis, Testing and Characterisation
}

\author{
D. Surrya Prakash, D. Praveen Kumar \\ Assistant Professor, ${ }^{2}$ Students, \\ Veltech Rangarajan Dr. Sagunthala R\&D Institute of Science and Technology, Avadi, Chennai-600062. India.
}

\begin{abstract}
The paper deals about the development, comparison, testing and analysis of composite materials and sandwich composite panels. In this paper we have carried out testing of mechanical and physical properties of coir composites, SMC laminate, Bamboo Composite, Cement bonded wooden particle composite. Then we have used SMC Laminate on coir composite so as to increase its strength. Also we have carried out tensile test for bamboo composite, coir composite, cement bonded composite. Then we have compared the values of these composites. Water absorption test and flame test of coir composite, Bamboo composite has been carried out, so as to find out the mechanical and physical properties of composite materials. Finally, Bending test and Analysis of sandwich composite panels has been carried out for bamboo-EPS sandwich panel and Bison-EPS sandwich panel to understand the characteristics of sandwich composite panels.
\end{abstract}

Keywords: Sandwich composite panels, Coir composites, SMC laminate, Bamboo Composite, Cement bonded wooden particle composite, testing and analysis.

\section{Introduction}

Composite materials are materials made from two or more constituent materials with significantly different physical or chemical properties, that when combined, produce a material with characteristics different from the individual components. The individual components remain separate and distinct within the finished structure.

Typical engineered composite materials include:

- Composite building materials such as cements, concrete

- Reinforced plastics such as fiber-reinforced polymer

- Metal Composites

- Ceramic Composites (composite ceramic and metal matrices)

Why composites are used in automobiles?

\section{Literature Review}

- To improve fuel efficiency by reducing mass of the vehicle

- To improve safety and crash worthiness

- To enhance styling and part consolidation

- To provide aero dynamic design

\subsection{FIBRE REINFORCED COMPOSITES (FRC)}

Fiber reinforced composites is a building material that consist of three components.

- The fibers as the discontinuous or dispersed phase.

- The matrix as the continuous phase.

- The fine inter phase region or inter phase.

\subsection{COIR FIBRES}

Coir fibers are found between the hard, internal shell and the outer coat of a coconut. The individual fibercellare narrow and hollow, with thick walls made of cellulose. They are pale when immature but later become hardened and yellowed as a layer of lignin is deposited on their walls. There are two varieties of coir fiber. Brown coir fibre is harvested from fully ripened coconuts. It is thick, strong and has high abrasion resistance. It is typically used in mats, brushes and sacking. 


\subsection{BAMBOO FIBRES}

Bamboo fiber is a cellulose fiber extracted or fabricated from natural bamboo (and possibly other additives) and is made from (or in the case of material fabrication, is) the pulp of bamboo plants. It is usually not made from the fibers of the plant, but is a synthetic viscose made from bamboo cellulose.

\subsection{Sandwich Composites}

A sandwich consists of three or more constituents: the faces, the core and the adhesives joints. In general the faces may be of different materials and even the two adhesives joints may be of different adhesives, all depending on the requirements of the structure. The choice of materials is vast and since the introduction of fiber composites the choice of face materials has increased to an almost infinite number of different materials, all with different properties.

The materials best suited for specific applications may be utilized and some drawbacks can be overcome by geometrical sizing. Materials are often chosen on grounds that are not purely mechanical but rather for reasons such as, environmental resistance, surface finish, the use of a specific manufacturing.

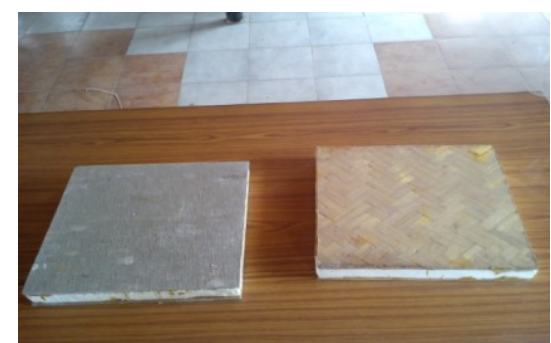

Fig.2.1: Bison Sandwich Composite (Left) Bamboo Sandwich Composite (Right)

\section{Advantages of a sandwich composite:}

The way that the sandwich enhances the flexural rigidity of a structure without adding substantial weight has made the concept even more advantageous since the introduction of composite materials These materials generally offer the same or even more Strength as compared to the metals such as aluminum or steel.

\section{COIR COMPOSITE}

Coir composite is a panel product manufacture from coir and other lignocellosic materials combined with synthetic resin or other suitable binder and is the latest development in the panel industry. The technology utilized to manufacture coir composite panel is an improvised combination of that used in the existing panel industry. Coir composite panel find application wherever other fibre panels of various types are being used.
Advantages:
- $\quad$ Light weight
- Unbreakable
- Non corrosive
- Water resistant
- Durable and affordable

\section{CLASSIFICATION:}

Coir composite are generally classified into three types according to their method of manufacture, density and other related mechanical and physical properties.

\section{1) Medium Coir Composite}

Coir composite sheets having uniform thickness and a density between $350 \mathrm{~kg} / \mathrm{m}^{3}$ and $800 \mathrm{~kg} / \mathrm{m}^{3}$.

2) Standard Coir Composite

Coir composite sheets having uniform thickness and a density exceeding $800 \mathrm{~kg} / \mathrm{m}^{3}$. 


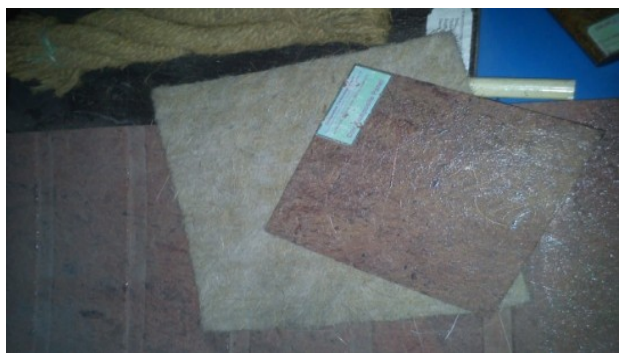

Fig. 3.1: COIR HARD BOARD

\section{APPLICATIONS:}

- Construction of bus bodies

- Prefabricated houses

- Panelling

- Partitions

- Furniture

\section{CEMENT BONDED WOOD PARTICLE COMPOSITE}

Product variants also available in amber, brick-red, anthracite (colored) - only for use indoors and for primed or finished facade panels.

\section{Applications:}

- Elevation panels

- Partitioning walls with mounting construction

- cladding for wet rooms

- fire-resistant construction

- noise-resistant constructions

- composite building system

\section{Tensile testing}

\section{Testing Composite}

1. Maximum load

2. Maximum stress

3. Extension at maximum load

4. Tensile strength

Physical Testing Of Coir Composite

- Water absorption test

- Hot water test

- Cold water test

- Flame test

\section{Applications}

- Electrical applications

- Corrosion resistant needs

- Structural components at low cost

- Automotive

\subsection{BENDING TEST ON SANDWICH COMPOSITE PANELS}

\section{Bending test:}

Bend testing determines the ductility or strength of a material by bending the material over a given radius. Following the bend, the sample is inspected for cracks on the outer surface. Bend testing provides insight into the Young's Modulus and the bending strength or the material.

\section{Materials selected:}

1. Bamboo-EPS sandwich panel

2. Bison-EPS sandwich panel

3.1.1 Bamboo-EPS Sandwich Panel 4'(Span)

Dimensions: (2442 x $1221 \times 90) \mathrm{mm}$ 
Young's modulus: $1.45 \mathrm{GPa}$

Poisson's ratio: 0.3

TABLE 3.1: Bending test for 4' (SPAN) bamboo-EPS sandwich panel (LOADING)

MAXIMUM DEFLECTION: $6 \mathrm{~mm}$

\begin{tabular}{|l|l|l|}
\hline SR NO. & LOAD $(\mathbf{K g})$ & DEFLECTION $(\mathbf{m m})$ \\
\hline 1 & 0 & 0 \\
\hline 2 & 21 & 0 \\
\hline 3 & 43 & 0 \\
\hline 4 & 66.1 & 2 \\
\hline 5 & 89.1 & 3 \\
\hline 6 & 112.6 & 3 \\
\hline 7 & 136.1 & 4 \\
\hline 8 & 159.3 & 5 \\
\hline 9 & 183 & 6 \\
\hline 10 & 201 & 6 \\
\hline
\end{tabular}

\section{Bamboo-EPS Sandwich Panel 6' (Span)}

Dimensions: $(2442 \times 1221$ x 90) $\mathrm{mm}$

Young's modulus: $1.45 \mathrm{GPa}$

Poisson's ratio: 0.3

TABLE 3.2: Bending test for 6' (SPAN) bamboo-EPS sandwich panel (LOADING)

\begin{tabular}{|l|l|l|}
\hline SR NO. & LOAD $(\mathbf{K g})$ & DEFLECTION $(\mathbf{m m})$ \\
\hline 1 & 0 & 0 \\
\hline 2 & 23.6 & 2 \\
\hline 3 & 46.6 & 3 \\
\hline 4 & 70.1 & 3 \\
\hline 5 & 93.2 & 4 \\
\hline 6 & 114.2 & 5 \\
\hline 7 & 137.3 & 5 \\
\hline 8 & 161 & 5 \\
\hline 9 & 181.9 & 6 \\
\hline 10 & 213.3 & 6 \\
\hline
\end{tabular}

Maximum deflection: $6 \mathrm{~mm}$

\subsubsection{Bamboo- EPS Sandwich Panel 8'(Span)}

Dimensions: (2442 x $1221 \times 90) \mathrm{mm}$

Young's modulus: $1.45 \mathrm{GPa}$

Poisson's ratio: 0.3

TABLE 3.3: Bending test for 8' (SPAN) bamboo-EPS sandwich panel (LOADING)

Maximum deflection: $9 \mathrm{~mm}$

\begin{tabular}{|l|l|l|}
\hline SR NO. & LOAD $\mathbf{( K g})$ & DEFLECTION $(\mathbf{m m})$ \\
\hline 1 & 0 & 0 \\
\hline 2 & 23.6 & 1 \\
\hline 3 & 47.2 & 2 \\
\hline 4 & 70.3 & 3 \\
\hline 5 & 91.3 & 4 \\
\hline 6 & 115 & 6 \\
\hline 7 & 138 & 6 \\
\hline 8 & 169.4 & 7 \\
\hline 9 & 192.5 & 8 \\
\hline 10 & 213.4 & 9 \\
\hline
\end{tabular}

\subsubsection{BISON - EPS Sandwich Panel4' (Span)}

Dimensions: 2442 x 1221 x 100

Young's modulus: $1.69 \mathrm{GPa}$

Poisson's ratio: 0.3

TABLE 3.4: Bending test for 4'(SPAN) Bison-EPS sandwich panel (LOADING)

\begin{tabular}{|l|l|l|}
\hline SR NO. & LOAD (Kg) & DEFLECTION (mm) \\
\hline 1 & 0 & 0 \\
\hline 2 & 23.7 & 0 \\
\hline 3 & 46.7 & 0 \\
\hline
\end{tabular}




\begin{tabular}{|l|l|l|}
\hline 4 & 67.7 & 0 \\
\hline 5 & 122.7 & 0 \\
\hline 6 & 166.7 & 1 \\
\hline 7 & 211.9 & 1 \\
\hline
\end{tabular}

Maximum deflection: $1 \mathrm{~mm}$

\subsubsection{BISON- EPS Sandwich Panel 6' (Span)}

Dimensions: 2442 × 1221 x 100

Young's modulus: $1.69 \mathrm{GPa}$

Poisson's ratio: 0.3

TABLE 3.5: Bending test for 6' (SPAN) Bison-EPS sandwich panel (LOADING)

Maximum deflection: $1 \mathrm{~mm}$

\begin{tabular}{|l|l|l|}
\hline SR NO. & LOAD $(\mathbf{K g})$ & DEFLECTION $(\mathbf{m m})$ \\
\hline 1 & 0 & 0 \\
\hline 2 & 31.4 & 0 \\
\hline 3 & 78.7 & 0 \\
\hline 4 & 120.69 & 0 \\
\hline 5 & 167.3 & 1 \\
\hline 6 & 212.5 & 1 \\
\hline
\end{tabular}

\subsubsection{BISON- EPS SANDWICH PANEL8' (SPAN)}

Dimensions: 2442 x 1221 x 100

Young's modulus: $1.69 \mathrm{GPa}$

Poisson's ratio: 0.3

TABLE 3.1.6: Bending test for 8'(SPAN) bison-EPS sandwich panel (LOADING)

\begin{tabular}{|l|l|l|}
\hline SR NO. & LOAD $(\mathbf{K g})$ & DEFLECTION $(\mathbf{m m})$ \\
\hline 1 & 0 & 0 \\
\hline 2 & 23.1 & 1 \\
\hline 3 & 44 & 2 \\
\hline 4 & 65 & 2 \\
\hline 5 & 88.7 & 2 \\
\hline 6 & 111.8 & 2 \\
\hline 7 & 135.4 & 3 \\
\hline 8 & 159 & 3 \\
\hline 9 & 182 & 3 \\
\hline 10 & 213.4 & 3 \\
\hline
\end{tabular}

Maximum deflection: $3 \mathrm{~mm}$

\section{Analysis Of Sandwich Composite Panels}

4.1 Bamboo-EPS Sandwich Panel 4' (Span)

Dimensions: (2442 x 1221 x 90) mm

Young's modulus: $1.45 \mathrm{GPa}$

Poisson's ratio: 0.3

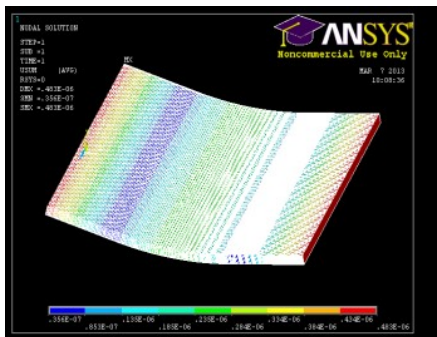

Fig 4.1: ANALYSIS OF BAMBOO-EPS SANDWICH PANEL 4'(SPAN)

\subsection{Bamboo-EPS Sandwich Panel 6' (Span)}

Dimensions: (2442 x 1221 x 90) $\mathrm{mm}$

Young's modulus: $1.45 \mathrm{GPa}$

Poisson's ratio: 0.3 


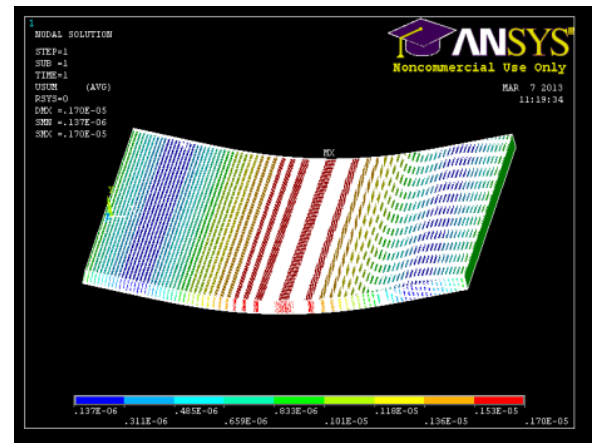

Fig 8.2: ANALYSIS OF BAMBOO-EPS SANDWICH PANEL 6'(SPAN)

4.3 Bamboo-EPS Sandwich Panel 8' (Span)

Dimensions: $(2442 \times 1221$ x 90) $\mathrm{mm}$

Young's modulus: $1.45 \mathrm{GPa}$

Poisson's ratio: 0.3

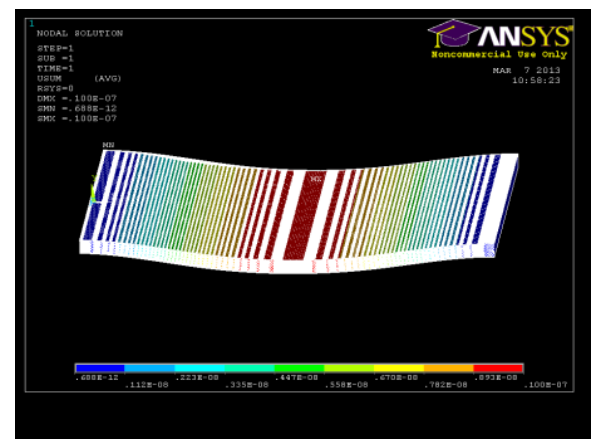

Fig 4.3: ANALYSIS OF BAMBOO-EPS SANDWICH PANEL 8'(SPAN)

\subsection{BISON-EPS Sandwich Panel 4' (Span)}

Dimensions: 2442 × $1221 \times 100$

Young's modulus: $1.69 \mathrm{GPa}$

Poisson's ratio: 0.3

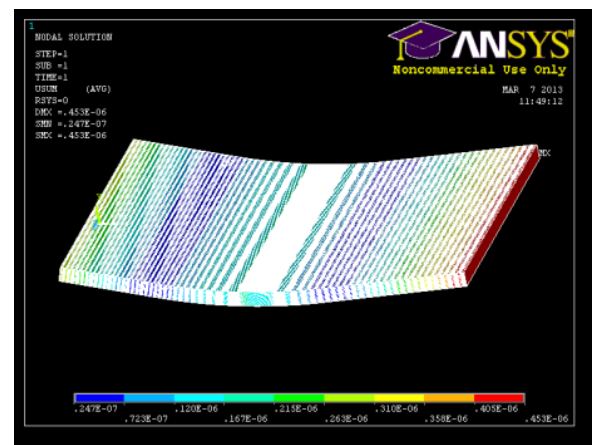

Fig 4.4: ANALYSIS OF BAMBOO-EPS SANDWICH PANEL 4'(SPAN)

\subsection{BISON-EPS Sandwich Panel 6' (Span)}

Dimensions: 2442 × 1221 x 100

Young's modulus: $1.69 \mathrm{GPa}$

Poisson's ratio: 0.3 


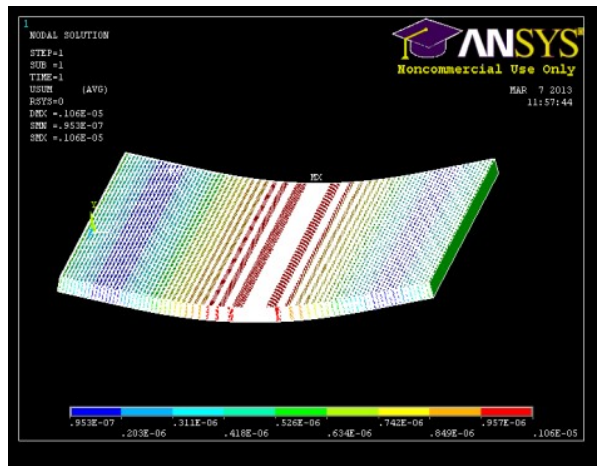

Fig 4.5: ANALYSIS OF BAMBOO-EPS SANDWICH PANEL 6'(SPAN)

\subsection{BISON-EPS Sandwich Panel 8'(Span)}

Dimensions: 2442 × $1221 \times 100$

Young's modulus: $1.69 \mathrm{GPa}$

Poisson's ratio: 0.3

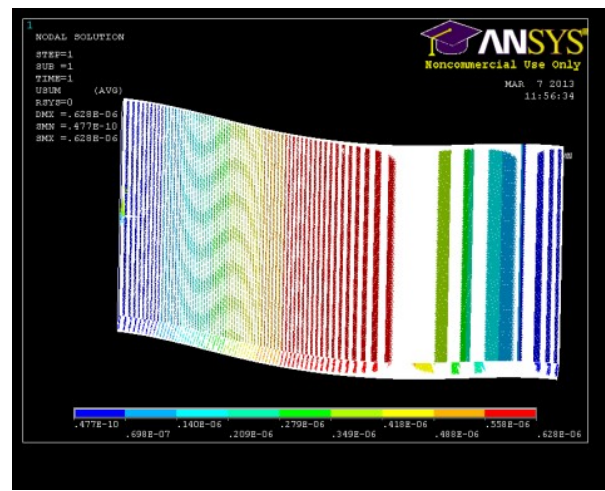

Fig 4.6: ANALYSIS OF BAMBOO-EPS SANDWICH PANEL 8'(SPAN)

\section{Conclusion}

Study on mechanical properties and physical properties of coir, Bamboo, bison and SMC-Coir hybrid composite is carried out.

Analysis is carried out to understand the characteristics of composite sandwich panel .And from the above results; we came to the conclusions that, bamboo-EPS sandwich panel can carry more loads by taking more deflection.

\section{Books:}

\section{References}

[1]. "A study of the differential scheme for composite materials",

[2]. R. McLaughlin.

[3]. "Application of Natural Fibre Composites in the Development of Rural Societies",

[4]. K. van Rijswijk, M. Sc. W. D. Brouwer, M. Sc.

[5]. Prof. A. Beukers, Structures and Materials Laboratory Faculty of Aerospace.

[6]. "Mechanics of Composite Materials",

[7]. George Z. Voyiadjis, Peter Kattan, Peter Issa Kattan.

[8]. "Engineering Composite Materials",

[9]. Bryan Harris.

[10]. WIKIPEDIA. 